Article

\title{
Aqueous Extract of Tomato (Solanum lycopersicum L.) and Ferulic Acid Reduce the Expression of TNF- $\alpha$ and IL-1 $\beta$ in LPS-Activated Macrophages
}

\section{Simón Navarrete ${ }^{1, *}$, Marcelo Alarcón ${ }^{2,3}$ and Iván Palomo ${ }^{2,3, *}$}

1 Immunology and Haematology Laboratory, Faculty of Health Sciences, Universidad de Talca, Talca 3460000, Chile

2 Department of Clinical Biochemistry and Immunohematology, Faculty of Health Sciences, Interdisciplinary Excellence Research Program on Healthy Aging (PIEI-ES), Universidad de Talca, Talca 3460000, Chile; E-Mail: malarcon@utalca.cl

3 Centro de Estudios en Alimentos Procesados (CEAP), CONICYT-Regional, Gore Maule R09I2001, Chile

* Authors to whom correspondence should be addressed; E-Mails: snavarretep@utalca.cl (S.N.); ipalomo@utalca.cl (I.P.); Tel.: +56-71-2201532 (S.N.); +56-71-2418825 (I.P.).

Academic Editor: Derek J. McPhee

Received: 8 June 2015 / Accepted: 17 August 2015/ Published: 21 August 2015

\begin{abstract}
Acute inflammation is essential for defending the body against pathogens; however, when inflammation becomes chronic, it is harmful to the body and is part of the pathophysiology of various diseases such as Diabetes Mellitus type 2 (DM2) and Cardiovascular Disease (CVD) among others. In chronic inflammation macrophages play an important role, mainly through the secretion of proinflammatory cytokines such as Tumor necrosis factor (TNF)- $\alpha$ and Interleukin (IL)-1 $\beta$, explained in part by activation of the Toll-like receptor 4 (TLR4), a signaling pathway which culminates in the activation of Nuclear factor (NF)- $\mathrm{B}$, an important transcription factor in the expression of these proinflammatory genes. On the other hand, the benefits on health of a diet rich in fruit and vegetables are well described. In this work, the effects of aqueous extract of tomato and ferulic acid on the expression of proinflammatory cytokines in LPS activated monocyte-derived THP-1 macrophages were investigated. In addition, using Western blot, we investigated whether the inhibition was due to the interference on activation of NF- $\kappa \mathrm{B}$. We found that both the tomato extract and ferulic acid presented inhibitory activity on the expression of TNF- $\alpha$ and IL-1 $\beta$ cytokine by inhibiting the activation
\end{abstract}


of NF-kB. The current results suggest that tomatoes and ferulic acid may contribute to prevention of chronic inflammatory diseases.

Keywords: inflammation; macrophages; proinflammatory cytokines; NF-кB

\section{Introduction}

Acute inflammation is the first response of the organism to control an insulting agent [1]. Macrophages are major players at the beginning of this process because they recognize microorganisms and dead cells, and produce various proinflammatory mediators such as Interleukin (IL)-1, TNF- $\alpha$, Interleukin (IL)-6, Prostaglandin E2 (PGE2) and NO [2]. These mediators activate endothelial cells and allow the arrival of more cells such as monocytes and neutrophils that fight the pathogen and release more inflammatory mediators [3-5].

THP-1 cells, a human monocytic cell line [6], can differentiate into macrophages by treatment with phorbol esters such as phorbol 12-myristate 13 acetate (PMA), that activates protein kinase C (PKC), mimicking the physiological activator diacylglycerol (DAG) [7]. Macrophages have different pathogen recognition receptors, including the main group of Toll-like receptor (TLR) [8]. Lipopolysaccharide (LPS) is recognized by TLR4 and activates a signaling pathway independent or Myeloid differentiation primary response gene 88 (MyD88)-dependent leading to the activation of NF- $\kappa \mathrm{B}$ and proinflammatory cytokine production. This signaling pathway is finely regulated to avoid damage to the organism induced by inflammation [9]. On the other hand, chronic inflammation is a maladapatative process, involved in the pathophysiology of obesity, insulin resistance, DM2 and CVD [10,11].

Functional foods are those found in a natural or processed form, that contain components that exert beneficial health effects that go beyond nutrition [12]. These functional foods possess bioactive compounds such as flavonoids, hydroxycinnamic acids, tannins, etc. [13]. There is epidemiological evidence that demonstrates the protective role of diets rich in fruit, vegetables, legumes, whole grains, nuts, unsaturated fats and fish on cancer and CVD [14,15]. It has been reported that tomato has beneficial effects on health, such as antiplatelet and antioxidant effects [16,17], besides cancer and CVD prevention [18]. Additionally, it has been shown to reduce systemic inflammation in women with obesity or overweight by decreasing serum proinflammatory cytokines [19]. In addition, tomato extract supplementation has been reported to decrease hepatic inflammation and total cholesterol in mice treated with a high-fat diet [20]. Ferulic acid, a hydroxycinnamic acid derivative, is present in tomatoes [21]; its concentration in aqueous tomato extract is approximately $4786.7 \pm 3 \mathrm{mg} / \mathrm{kg}$ [22]. This molecule has been found to attenuate cerebral ischemia in mice [23]. It has also been reported that it attenuates the expression of iNOS in LPS-stimulated RAW 264.7 macrophages [24] and CXCL2 in the same cell line in response to respiratory syncytial virus infection [25]. In addition, it has been described that ferulic acid has protective effect on the endothelium, attenuating the expression of adhesion molecules in gamma-radiated human umbilical vascular endothelial cells [26]. In this work, we evaluated the effect of tomato extract and ferulic acid on the expression of proinflammatory cytokines TNF- $\alpha$ and IL- $1 \beta$ and its impact on the activation of $\mathrm{NF}-\kappa \mathrm{B}$ in LPS-activated macrophages. 


\section{Results}

\subsection{Viability Study in Macrophages Incubated with Aqueous Tomato Extract and Ferulic Acid}

Table 1 shows the viability of macrophages incubated with tomato extract and ferulic acid, inactivated and activated with LPS. No significant differences between viability of cells incubated with tomato extract or ferulic acid, activated and inactivated, and the macrophages without aqueous tomato extract neither ferulic acid.

Table 1. Aqueous tomato extract and ferulic acid does not affect the viability of macrophages.

\begin{tabular}{cccccc}
\hline \multirow{2}{*}{ Aqueous Tomato Extract $(\mathbf{m g} / \mathbf{m L})$} & \multicolumn{2}{c}{ Viability by Trypan Blue (\%) } & \multicolumn{2}{c}{ Viability by MTT (\%) } \\
\cline { 2 - 3 } & Unactivated & Activated & Unactivated & Activated \\
\hline 0 & $99.3 \pm 0.8$ & $96.9 \pm 2.4$ & 100.0 & $98.0 \pm 1.3$ \\
0.1 & $94.0 \pm 0.5$ & $98.4 \pm 1.0$ & $96.9 \pm 3.4$ & $96.9 \pm 2.6$ \\
0.5 & $98.2 \pm 0.6$ & $95.4 \pm 4.0$ & $99.1 \pm 0.4$ & $96.5 \pm 2.1$ \\
1.0 & $97.7 \pm 1.1$ & $96.9 \pm 2.4$ & $95.4 \pm 4.2$ & $95.4 \pm 4.0$ \\
\hline Ferulic Acid $(\boldsymbol{\mu M})$ & & & & \\
\hline 125 & $99.5 \pm 0.5$ & $96.9 \pm 2.4$ & 100.0 & $98.0 \pm 1.3$ \\
250 & $97.9 \pm 0.7$ & $97.0 \pm 1.1$ & $96.0 \pm 0.4$ & $94.6 \pm 0.6$ \\
500 & $94.9 \pm 1.0$ & $95.0 \pm 0.6$ & $95.1 \pm 0.3$ & $98.0 \pm 0.7$ \\
\cline { 1 - 3 } & $96.3 \pm 1.0$ & $96.9 \pm 2.4$ & $97.7 \pm 2.1$ & $95.4 \pm 4.0$ \\
\hline
\end{tabular}

Means \pm S.E.M.; MTT, 3-(4,5-dimethylthiazol-2-yl)-2,5-diphenyltetrazolium bromide.

\subsection{Gene Expression Kinetics of TNF- $\alpha$ and IL-1 $\beta$ in LPS-Activated Macrophages and Effect of} Aqueous Tomato Extract and Ferulic Acid on the Expression of These Cytokines

The peak for TNF- $\alpha$ expression and IL-1 $\beta$ occurred at four hours post LPS activation at the two concentrations evaluated, however, the highest expression was obtained with LPS $1000 \mathrm{ng} / \mathrm{mL}$ (Figure 1). Figure 2 shows the relative expression of TNF- $\alpha$ and IL-1 $\beta$ in unactivated macrophages, activated with LPS, and incubated with aqueous tomato extract and ferulic acid for one hour and then activated with LPS. Macrophages incubated with aqueous tomato extract and ferulic acid had a lower expression of both cytokines compared to control (activated with LPS) $(p<0.05)$.
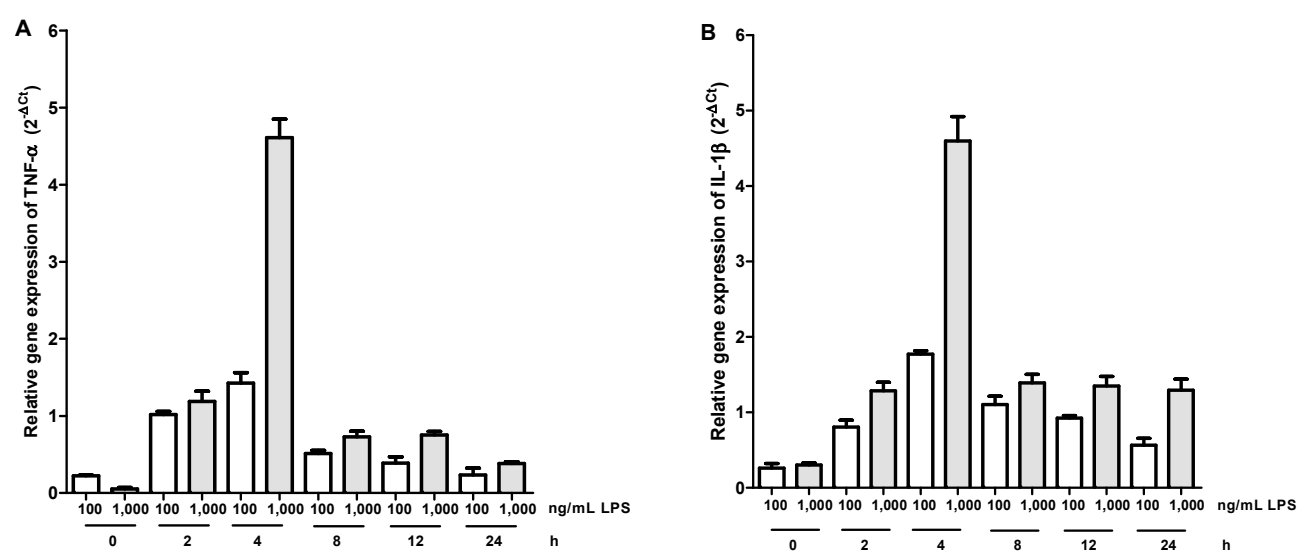

Figure 1. Gene expression kinetics of TNF- $\alpha(\mathbf{A})$ and IL-1 $\beta(\mathbf{B})$. It is observed that the peak of expression for both cytokines was $4 \mathrm{~h}$. 

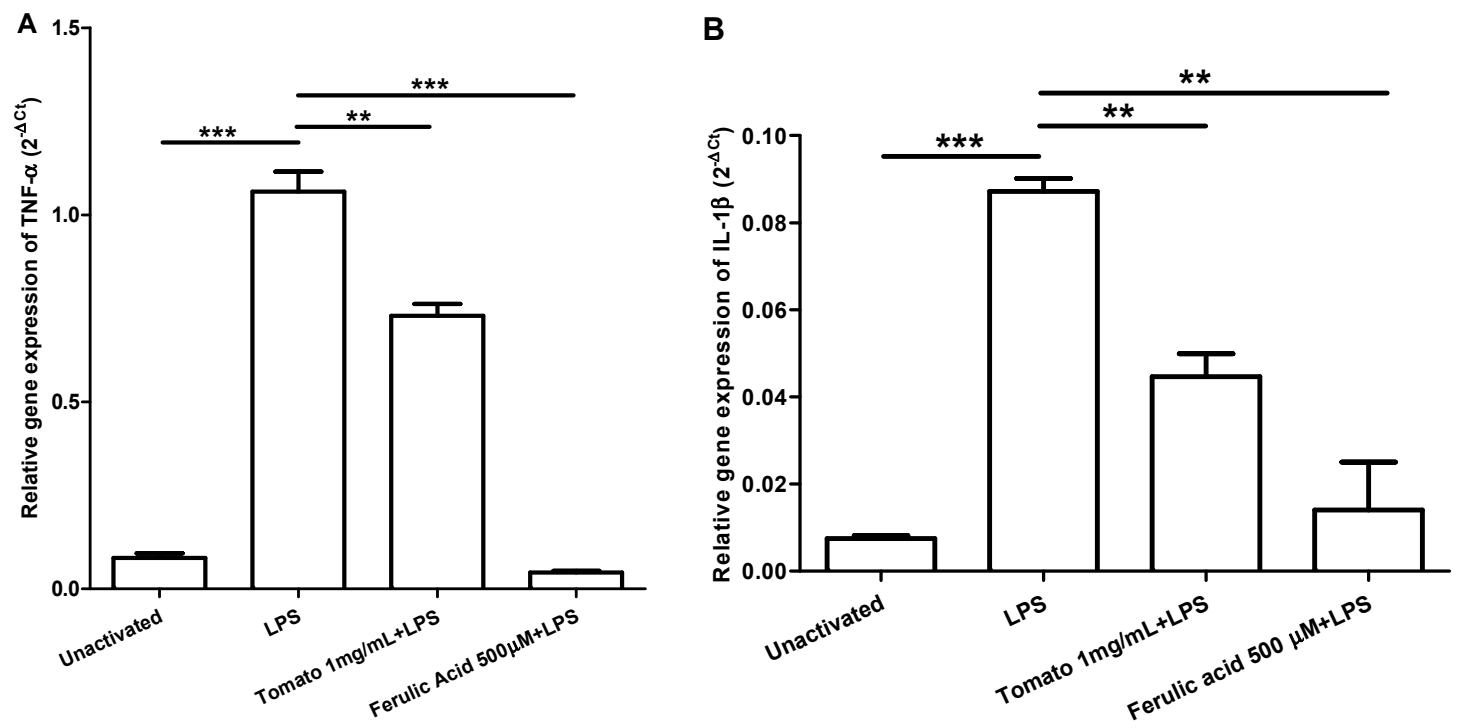

Figure 2. Aqueous tomato extract and ferulic acid inhibit expression of TNF- $\alpha(\mathbf{A})$ and IL-1 $\beta$ (B) in LPS-activated macrophages. LPS, lipopolysaccharide. ${ }^{* *}$ significant at the $p<0.01$ level, *** significant at the $p<0.001$ level.

\subsection{Kinetics of NF- $\mathrm{B}$ Activation in LPS-Activated Macrophages and Effect of Aqueous Tomato Extract and Ferulic Acid on Activation of This Transcription Factor}

Figure 3 shows that the peak activation of NF- $\mathrm{KB}$ was at $30 \mathrm{~min}$ post LPS in macrophages. Figure 4 shows that both tomato extract and ferulic acid inhibit NF- $\kappa B$ phosphorylation in LPS activated $(p<0.05)$ macrophages, previously incubated $1 \mathrm{~h}$ with these components, compared to control (activated macrophages).
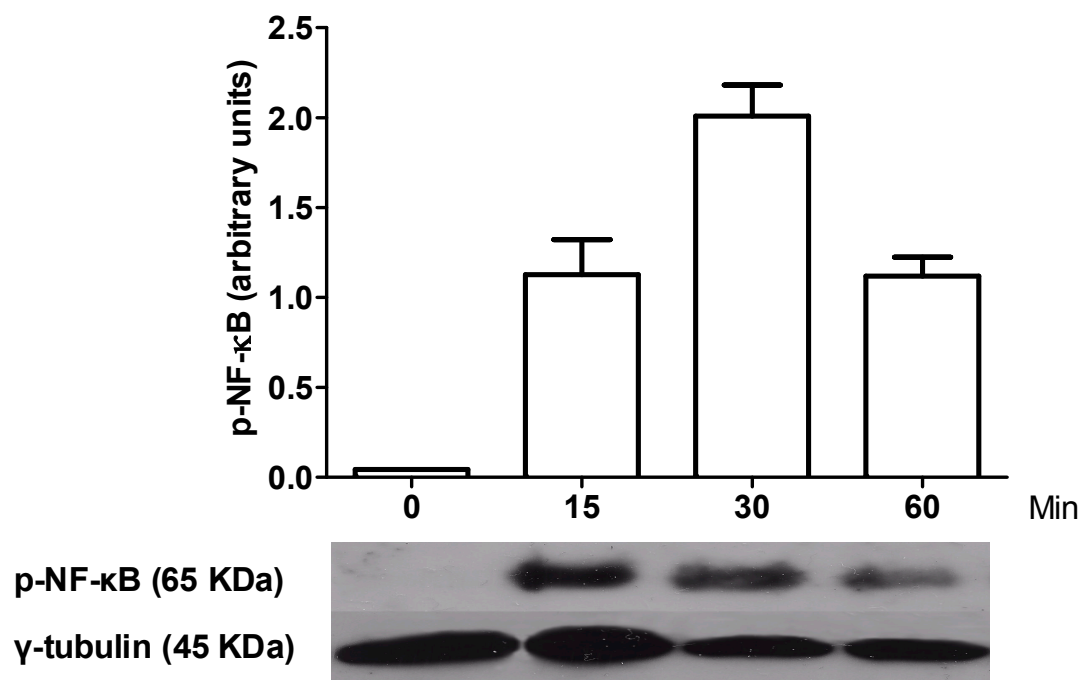

Figure 3. Kinetics of activation of NF- $\kappa \mathrm{B}$ in LPS-activated macrophages. It is observed that the peak of NF- $\kappa \mathrm{B}$ activation occurred at $30 \mathrm{~min}$ after the challenge with LPS. 


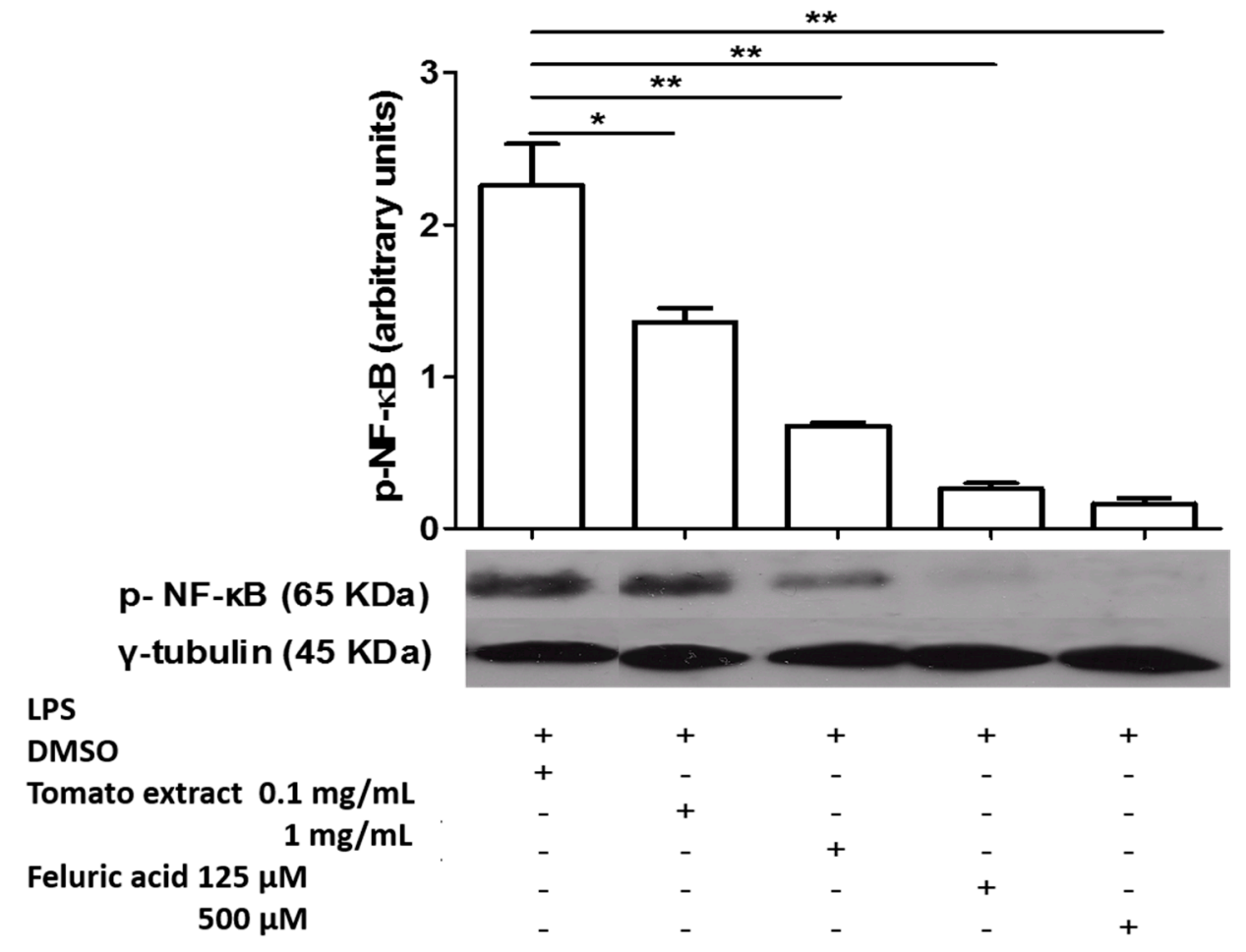

Figure 4. Extract tomato and Ferulic Acid inhibit the activation of NF- $\kappa$ B in LPS-activated macrophages. LPS, lipopolysaccharide; DMSO, dimethylsulfoxide, * significant at the $p<0.05$ level, ** significant at the $p<0.01$ level.

\section{Discussion}

The acute inflammatory response is essential to fight infections, but when this response becomes chronic, it is harmful to the organism as part of pathophysiology of diseases such as type 2 diabetes and CVD [27]. In this response, macrophages play an important role, through the production of proinflammatory cytokines. It has been reported that in obese people there is an increase in macrophage infiltration in the adipose tissue [28] and these macrophages polarize to a proinflammatory phenotype (M1) [29]. The increase in TNF- $\alpha$ promotes additional proinflammatory cytokine secretion and reduces anti-inflammatory cytokines such as adiponectin. TNF- $\alpha$ promotes insulin resistance by inhibiting the IRS1 (insulin receptor substrate 1) signaling pathway [30,31]. Additionally, IL-1 $\beta$ is toxic for the $\beta$-pancreatic cells causing apoptosis, thereby decreasing the production of insulin [32]. It is known that a diet high in fruits, vegetables, legumes, cereals, and fish, among others is beneficial to health [33,34]. In this study, we found that the aqueous extract of tomato and ferulic acid inhibit the expression of TNF- $\alpha$ and IL-1 $\beta$ in LPS-stimulated macrophages, through the inhibition of NF- $\kappa \mathrm{B}$.

In the literature, there are no reports regarding the effect of tomato extract on the proinflammatory cytokine production in macrophages derived from the cell line THP-1, activated with LPS. Nevertheless, there are studies reporting that some components of tomato inhibit inflammatory mediators. Rafi et al. reported that lycopene inhibits NO production in murine macrophage cell line RAW 264.7, through the inhibition of the expression of iNOS gene, expression that is coordinated primarily by NF- $\mathrm{B}$ [35]. Meanwhile, Dou et al. showed that the flavonoid naringenin, found in tomatoes, inhibits the production of several proinflammatory mediators such as iNOS, ICAM-1, Cox 2 , TNF- $\alpha$ and IL-6 in a murine model 
of intestinal inflammation, through attenuation of NF- $\kappa \mathrm{B}$ activation [36]. These findings are consistent with our observation that tomato extract contains several components able to inhibit cytokine synthesis.

In the same vein, we verified that ferulic acid, a derivative of hydroxycinnamic acid present in tomatoes, had the same effect as tomato extract. In this regard, Sakai et al. reported that ferulic acid and isoferulic acid exerted an inhibitory effect on the production of CXCL2 in RAW 264.7 macrophages [25], where this chemokine may have been induced by stimulation with LPS [37]. Furthermore, Kim et al. showed that ferulic acid inhibits the expression of iNOS in RAW 264.7 macrophages stimulated with LPS again, through the inhibition of NF- $\kappa \mathrm{B}$ [24]. These studies support our results, since they describe inhibition of the expression of effectors produced by the activation of the same inflammatory pathway. Furthermore, it has also been reported that a ferulic acid derivative, ferulic acid ethyl ester, inhibit the translocation of NF- $\mathrm{BB}$ in RAW 264.7 macrophages stimulated with LPS [38]. Nagasaka et al., found that cycloartenil ferulate inhibits expression of iNOS and COX-2 by inhibition of NF- $\kappa$ B [39]. Other studies have also shown that some ferulic acid derivatives have potent inhibitory effects on inflammation, while ferulic acid showed less potency. Murakami et al. found that FA15, a ferulic acid derivative markedly inhibited the expression of iNOS and COX-2 and TNF- $\alpha$ secretion by inhibition of IkB degradation in RAW 264.7 macrophages, while ferulic acid poorly exhibited this effect [40]. Roncheti et al. also showed that NCX 2057, another ferulic acid derivative, inhibited the expression of iNOS in RAW 264.7 macrophages activated with LPS/IFN- $\gamma$, in contrast to ferulic acid [41]. Finally, Hirata et al. showed that ferulic acid derivatives have inhibitory effect on the expression of COX-2 in RAW 264.7 macrophages stimulated with LPS, but ferulic acid has no such effect. [42].

Importantly, LPS-signaling that is activated in macrophages via TLR4 is complex and involves several kinases. After binding to its receptor, the signal is transmitted by different adapter proteins: TIRAP (Toll-interleukin 1 receptor domain-containing adapter protein) and MyD88 (Myeloid differentiation primary response gene 88) driving the MyD88-dependent pathway, while TRAM (TRIF-related adaptor molecule) and TRIF (TIR-domain-containing adapter-inducing interferon- $\beta$ ) driving the MyD88-independent pathway [43]. The first pathway follows the activation of IRAK 1 and 4 (IL-1R activated kinases 1 and 4), TRAF6 (Tumor necrosis factor (TNF)-receptor-associated factor 6) and TAK1 (Transforming growth factor- $\beta$-activated kinase 1). The MyD88-independent pathway activation continues with RIP-1 (Receptor interacting protein 1) and TRAF3. Finally, the MyD88-dependent pathway converges in IKK (IאB kinase) and MAPK (Mitogen-activated protein kinases) activation and subsequent activation of NF- $\mathrm{B}$ and activator protein (AP)-1 [9]. Given the complexity of the signaling pathway that activates NF- $\kappa \mathrm{B}$ additional studies are needed to establish the stage where the tomato extract and ferulic acid produce inhibition.

\section{Experimental Section}

\subsection{Cell Culture and Macrophage Differentiation}

The THP-1 cells were expanded in culture medium RPMI 1640 1X (Gibco, Grand Island, NY, USA) supplemented with inactivated fetal bovine serum (FBS; Cellgro, Manassas, VA, USA) to 10\%, penicillin/streptomycin (Gibco) to 1\% and 2-Mercaptoethanol (Amresco, Solon, OH, USA) $0.05 \mathrm{mM}$, in a humidified incubator at $37{ }^{\circ} \mathrm{C}$ and $5 \% \mathrm{CO}_{2}$. The culture medium was renewed every 3 days and the assays were performed at passage 10 . 
Differentiation of THP-1 cells to macrophage was induced with phorbol 12-myristate 13 acetate (PMA, Sigma-Aldrich, St. Louis, MO, USA) at final concentration of $160 \mathrm{ng} / \mathrm{mL}$, in 24 well plates, where cell concentration was $1 \times 10^{6}$ cells $/ \mathrm{mL}$ and the final volume was $500 \mu \mathrm{L}$. Cells were incubated $48 \mathrm{~h}$, the culture medium was renewed, and incubated for an additional $24 \mathrm{~h}$. After this period of time, macrophages M0 were obtained, according to the literature [25].

\subsection{Aqueous Extract of Tomato and Ferulic Acid}

The aqueous extract of tomato was prepared as follows: small pieces of red tomato pulp (free of seeds) were comminuted in a blender, and the resulting mash was filtered through gauze twice. The liquid obtained was lyophilized and stored at $-80{ }^{\circ} \mathrm{C}$. At the time of use, this was diluted in distilled water, sonicated and filtered $(0.22 \mu \mathrm{m}$ pore size $)$. The final concentrations used were $0.1,0.5$ and $1 \mathrm{mg} / \mathrm{mL}$. Commercial ferulic acid (Sigma-Aldrich) was used and prepared in distilled water plus DMSO (concentration in culture $<1 \%$ ), sonicated and then filtered through a syringe filter $0.22 \mu \mathrm{m}$. Final concentrations used were 125,250 and $500 \mu \mathrm{M}$.

\subsection{Viability Study by Trypan Blue Exclusion and Reduction of Bromide 3-(4,5-Dimethyl-2-thiazoyl)- 2,5-difeniltetrazólico (MTT)}

Macrophages were incubated with tomato extracts and ferulic acid to the maximum concentration used $(1 \mathrm{mg} / \mathrm{mL}$ and $500 \mu \mathrm{M}$, respectively) or DMSO for $24 \mathrm{~h}$. To determine viability by Trypan Blue exclusion, $50 \mu \mathrm{L}$ of $1 \mathrm{X}$ Trypsin (SAFC Biosciences, Inc., Lenexa, KS, USA) was added to each well, incubated at $37{ }^{\circ} \mathrm{C}$ for $3 \mathrm{~min}$ and resuspended in $500 \mu \mathrm{L}$ of medium. An aliquot of $100 \mu \mathrm{L}$ of cell suspension was mixed with $800 \mu \mathrm{L}$ of sterile PBS and $100 \mu \mathrm{L}$ of $4 \%$ Trypan Blue (Gibco). Then the mixture was homogenized and loaded in a Neubauer chamber. Viability was calculated as follows: \% viable cells $=[1.00-($ number of blue cells $/$ total cells $)] \times 100$. To determine viability by MTT to each well were added $200 \mu \mathrm{L}$ of MTT solution ( $50 \mu \mathrm{L}$ of MTT $5 \mathrm{mg} / \mathrm{mL}$ and $150 \mu \mathrm{L}$ of RPMI supplemented), then incubated for $4 \mathrm{~h}$ at $37^{\circ} \mathrm{C}$, washed with sterile PBS and $200 \mu \mathrm{L}$ of lysate solution $0.04 \mathrm{~N}$ is added ( $10 \mu \mathrm{L}$ of $\mathrm{HCl}$ to $3000 \mu \mathrm{L}$ of isopropanol) and the lysate was centrifuged at 12,000 rpm for 5 min and absorbance was measured between 570 and $630 \mathrm{~nm}$. Control absorbance, macrophages without aqueous extract tomato or ferulic acid, is considered $100 \%$ viability.

\subsection{Expression of Proinflammatory Cytokines}

The peak of expression for TNF- $\alpha$ and IL-1 $\beta$ was determined in addition to the concentration of LPS used. First macrophages were activated with LPS (E. coli 0111: B4, Sigma-Aldrich) at $100 \mathrm{ng} / \mathrm{mL}$ or $1000 \mathrm{ng} / \mathrm{mL}$ and incubated for $0,2,4,8,12$ and $24 \mathrm{~h}$ in culture oven. mRNA extraction was done with the EZNA ${ }^{\circledR}$ kit (Omega Bio-Tek, Norcross, GA, USA), according to manufacturer's instructions. To synthesize cDNA, the AffinityScript QPCR cDNA Synthesis kit was used. The real-time PCR was done with the Brilliant SYBR Green QPCR Master Mix. The primers, forward and reverse, respectively, were as follows: TNF- $\alpha$ (CCGTCTCCTACCAGACCAAGG, CTGGAAGACCCCTCCCAGATAG), IL-1 $\beta$ (CCCACAGACCTTCCAGGAGA, CGGAGCGTGCAGTTCAGTG) and for the reference gene $\beta 2$-microglobulin (GCTCCGTGGCCTTAGCTGT, ACGTGAGTAAACCTGAATCTTTGGA), 
all used to the concentration of $400 \mathrm{nM}$ and $40 \mathrm{ng}$ of cDNA were used in a final volume of $25 \mu \mathrm{L}$. An initial cycle of $10 \mathrm{~min}$ at $95{ }^{\circ} \mathrm{C}$ was programmed followed by 40 cycles of $30 \mathrm{~s}$ at $95{ }^{\circ} \mathrm{C}, 1 \mathrm{~min}$ at $60{ }^{\circ} \mathrm{C}$ and $30 \mathrm{~s}$ at $72{ }^{\circ} \mathrm{C}$. The relative gene expression for both cytokines was calculated by $2^{-\Delta \mathrm{Ct}}$ method $\left(2^{-(\mathrm{Ct}(\text { gene of interest) }) \mathrm{Ct}(\text { (reference gene) })}\right)$. To evaluate the effect of tomato extract and ferulic acid on the expression of TNF- $\alpha$ and IL-1 $\beta$, macrophages were incubated with different concentrations of these compounds or DMSO at final concentration of $1 \%$ for $1 \mathrm{~h}$. Then, macrophages were activated with LPS $1000 \mathrm{ng} / \mathrm{mL}$ and incubated for $4 \mathrm{~h}$ to proceed as mentioned above.

\subsection{Western Blotting for Phospho-NF-кB p65 (Ser536)}

First macrophages were activated at $0,15,30$ and $60 \mathrm{~min}$ with LPS a $1000 \mathrm{ng} / \mathrm{mL}$, to determine the peak of activation for NF- $\kappa$ B. Then, the cells were lysed with RIPA buffer (Sigma-Aldrich). Protein concentration was measured by BCA method (BCA Protein Assay TM Pierce, Thermo Scientific, Rockford, IL, USA) and $2 \mu \mathrm{g}$ of total protein was loaded on SDS-PAGE. The primary antibody rabbit IgG anti-Phospho-NF-кB p65 (Ser536) (Cell Signaling Technology, Beverly, MA, USA) and the loading control antibody rabbit IgG anti- $\gamma$-Tubulin (Thermo Scientific) were used. As secondary antibody, anti-rabbit IgG peroxidase conjugate (Sigma, Saint Louis, MO, USA) was used. After incubation with the secondary antibody, the membrane was incubated with ECL Western blotting Substrate Pierce (Thermo Scientific) for one min. Then, the film (CL-XPosure ${ }^{\mathrm{TM}}$ Film, Thermo Scientific) was exposed to the membrane for $15 \mathrm{~min}$ and developed. To evaluate the effect of aqueous tomato extract and ferulic acid on activation of NF- $\mathrm{KB}$, macrophages were incubated with different concentrations of these or DMSO at final concentration of $1 \%$ for $1 \mathrm{~h}$, and then activated with LPS to $1000 \mathrm{ng} / \mathrm{mL}$ for $30 \mathrm{~min}$.

\subsection{Statistical Analysis}

Data were analyzed using GraphPad Prism 5 software for Windows. Normality test was made and the results are expressed as mean plus standard error. To analyze the statistical significance of differences between control and test values obtained $t$-Student was used considered statistically significant differences with $p<0.05$ (* $p<0.05, * * p<0.01$ and $* * * p<0.001)$.

\section{Conclusions}

The aqueous extract of tomato has an inhibitory effect on the production of TNF- $\alpha$ and IL-1 $\beta$ in LPS-activated macrophages. This effect is due to the action of several compounds present in tomatoes having an anti-inflammatory effect. One of these compounds is ferulic acid, which also inhibits the expression of these cytokines. This inhibition is due to inhibition of NF- $\kappa \mathrm{B}$ activation. However, the signaling pathway that leads to the activation of this transcription factor comprises several protein kinases. Therefore, further studies are needed to identify the exact target. Since these proinflammatory cytokines exert different functions in the pathology of chronic diseases, consumption of these elements may be beneficial in preventing the onset of diseases such as diabetes and CVD or mitigate their effects.

\section{Acknowledgments}

This work was funded by by grant No. 1130216 (I.P., M.G., R.M., M.A., J.C.) from Fondecyt, Chile. 


\section{Author Contributions}

S.N. and M.A. conceived and designed the experiments; S.N. and M.A. performed the experiments; S.N. and M.A. analyzed the data; I.P and M.A. contributed reagents/materials/analysis tools; S.N. and I.P. wrote the paper.

\section{Conflicts of Interest}

The authors declare no conflict of interest.

\section{References}

1. Larsen, G.L.; Henson, P.M. Mediators of inflammation. Annu. Rev. Immunol. 1983, 1, 335-359.

2. Erwig, L.P.; Rees, A.J. Macrophage activation and programming and its role for macrophage function in glomerular inflammation. Kidney Blood Press. Res. 1999, 22, 21-25.

3. Lawrence, T.; Willoughby, D.A.; Gilroy, D.W. Anti-inflammatory lipid mediators and insights into the resolution of inflammation. Nat. Rev. Immunol. 2002, 2, 787-795.

4. Kobayashi, S.D.; Voyich, J.M.; Burlak, C.; DeLeo, F.R. Neutrophils in the innate immune response. Arch. Immunol. Ther. Exp. (Warsz) 2005, 53, 505-517.

5. Italiani, P.; Boraschi, D. From Monocytes to M1/M2 Macrophages: Phenotypical vs. Functional Differentiation. Front. Immunol. 2014, 5, 514, doi:10.3389/fimmu.2014.00514.

6. Tsuchiya, S.; Yamabe, M.; Yamaguchi, Y.; Kobayashi, Y.; Konno, T.; Tada, K. Establishment and characterization of a human acute monocytic leukemia cell line (THP-1). Int. J. Cancer 1980, 26, 171-176.

7. Schwende, H.; Fitzke, E.; Ambs, P.; Dieter, P. Differences in the state of differentiation of THP-1 cells induced by phorbol ester and 1,25-dihydroxyvitamin D3. J. Leukoc. Biol. 1996, 59, 555-561.

8. Wang, J.Q.; Jeelall, Y.S.; Ferguson, L.L.; Horikawa, K. Toll-Like Receptors and Cancer: MYD88 Mutation and Inflammation. Front. Immunol. 2014, 5, 367, doi:10.3389/fimmu.2014.00367.

9. Lu, Y.C.; Yeh, W.C.; Ohashi, P.S. LPS/TLR4 signal transduction pathway. Cytokine 2008, 42, $145-151$.

10. Hotamisligil, G.S. Inflammation and metabolic disorders. Nature 2006, 444, 860-867.

11. Gregor, M.F.; Hotamisligil, G.S. Inflammatory mechanisms in obesity. Annu. Rev. Immunol. 2011, $29,415-445$.

12. Diplock, A.T.; Aggett, P.J.; Ashwell, M.; Bornet, F.; Fern, E.B.; Roberfroid, M.B. Scientific concepts of functional foods in Europe: Consensus document. Br. J. Nutr. 1999, 81 (Suppl 1), S1-S27.

13. Ignat, I.; Volf, I.; Popa, V.I. A critical review of methods for characterisation of polyphenolic compounds in fruits and vegetables. Food Chem. 2011, 126, 1821-1835.

14. Kris-Etherton, P.M.; Hecker, K.D.; Bonanome, A.; Coval, S.M.; Binkoski, A.E.; Hilpert, K.F.; Griel, A.E.; Etherton, T.D. Bioactive compounds in foods: Their role in the prevention of cardiovascular disease and cancer. Am. J. Med. 2002, 113 (Suppl 9B), 71S-88S.

15. Widmer, R.J.; Flammer, A.J.; Lerman, L.O.; Lerman, A. The Mediterranean Diet, its Components, and Cardiovascular Disease. Am. J. Med. 2014, 128, 229-238. 
16. O’Kennedy, N.; Crosbie, L.; Whelan, S.; Luther, V.; Horgan, G.; Broom, J.I.; Webb, D.J.; Duttaroy, A.K. Effects of tomato extract on platelet function: A double-blinded crossover study in healthy humans. Am. J. Clin. Nutr. 2006, 84, 561-569.

17. Fuentes, E.; Carle, R.; Astudillo, L.; Guzman, L.; Gutierrez, M.; Carrasco, G.; Palomo, I. Antioxidant and Antiplatelet Activities in Extracts from Green and Fully Ripe Tomato Fruits (Solanum lycopersicum) and Pomace from Industrial Tomato Processing. Evid. Based Complement. Altern. Med. 2013, 2013, doi:10.1155/2013/867578.

18. Blum, A.; Monir, M.; Wirsansky, I.; Ben-Arzi, S. The beneficial effects of tomatoes. Eur. J. Intern. Med. 2005, 16, 402-404.

19. Ghavipour, M.; Saedisomeolia, A.; Djalali, M.; Sotoudeh, G.; Eshraghyan, M.R.; Moghadam, A.M.; Wood, L.G. Tomato juice consumption reduces systemic inflammation in overweight and obese females. Br. J. Nutr. 2013, 109, 2031-2035.

20. Melendez-Martinez, A.J.; Nascimento, A.F.; Wang, Y.; Liu, C.; Mao, Y.; Wang, X.D. Effect of tomato extract supplementation against high-fat diet-induced hepatic lesions. Hepatobiliary Surg. Nutr. 2013, 2, 198-208.

21. Mattila, P.; Kumpulainen, J. Determination of free and total phenolic acids in plant-derived foods by HPLC with diode-array detection. J. Agric. Food Chem. 2002, 50, 3660-3667.

22. Fuentes, E.; Forero-Doria, O.; Carrasco, G.; Marican, A.; Santos, L.S.; Alarcon, M.; Palomo, I. Effect of tomato industrial processing on phenolic profile and antiplatelet activity. Molecules 2013, 18 , $11526-11536$.

23. Sung, J.H.; Gim, S.A.; Koh, P.O. Ferulic acid attenuates the cerebral ischemic injury-induced decrease in peroxiredoxin-2 and thioredoxin expression. Neurosci. Lett. 2014, 566, 88-92.

24. Kim, E.O.; Min, K.J.; Kwon, T.K.; Um, B.H.; Moreau, R.A.; Choi, S.W. Anti-inflammatory activity of hydroxycinnamic acid derivatives isolated from corn bran in lipopolysaccharide-stimulated Raw 264.7 macrophages. Food Chem. Toxicol. 2012, 50, 1309-1316.

25. Sakai, S.; Kawamata, H.; Kogure, T.; Mantani, N.; Terasawa, K.; Umatake, M.; Ochiai, H. Inhibitory effect of ferulic acid and isoferulic acid on the production of macrophage inflammatory protein-2 in response to respiratory syncytial virus infection in RAW264.7 cells. Mediat. Inflamm. 1999, 8, 173-175.

26. Ma, Z.C.; Hong, Q.; Wang, Y.G.; Tan, H.L.; Xiao, C.R.; Liang, Q.D.; Cai, S.H.; Gao, Y. Ferulic acid attenuates adhesion molecule expression in gamma-radiated human umbilical vascular endothelial cells. Biol. Pharm. Bull. 2010, 33, 752-758.

27. Emanuela, F.; Grazia, M.; Marco, D.R.; Maria Paola, L.; Giorgio, F.; Marco, B. Inflammation as a Link between Obesity and Metabolic Syndrome. J. Nutr. Metab. 2012, 2012, doi:10.1155/2012/476380.

28. Torres-Leal, F.L.; Fonseca-Alaniz, M.H.; Rogero, M.M.; Tirapegui, J. The role of inflamed adipose tissue in the insulin resistance. Cell Biochem. Funct. 2010, 28, 623-631.

29. Mraz, M.; Haluzik, M. The role of adipose tissue immune cells in obesity and low-grade inflammation. J. Endocrinol. 2014, 222, R113-R127.

30. Wang, B.; Trayhurn, P. Acute and prolonged effects of TNF-alpha on the expression and secretion of inflammation-related adipokines by human adipocytes differentiated in culture. Pflug. Arch. 2006, 452, 418-427. 
31. Hotamisligil, G.S.; Peraldi, P.; Budavari, A.; Ellis, R.; White, M.F.; Spiegelman, B.M. IRS-1-mediated inhibition of insulin receptor tyrosine kinase activity in TNF-alpha- and obesity-induced insulin resistance. Science 1996, 271, 665-668.

32. Dinarello, C.A.; van der Meer, J.W. Treating inflammation by blocking interleukin-1 in humans. Semin. Immunol. 2013, 25, 469-484.

33. Karampola, M.; Papandreou, D.; Makedou, K. The role of Mediterranean diet in health and disease: An updated mini review. Nutr. Food Sci. 2011, 41, 63-72.

34. Boeing, H.; Bechthold, A.; Bub, A.; Ellinger, S.; Haller, D.; Kroke, A.; Leschik-Bonnet, E.; Muller, M.J.; Oberritter, H.; Schulze, M.; et al. Critical review: Vegetables and fruit in the prevention of chronic diseases. Eur. J. Nutr. 2012, 51, 637-663.

35. Rafi, M.M.; Yadav, P.N.; Reyes, M. Lycopene inhibits LPS-induced proinflammatory mediator inducible nitric oxide synthase in mouse macrophage cells. J. Food Sci. 2007, 72, S069-S074.

36. Dou, W.; Zhang, J.; Sun, A.; Zhang, E.; Ding, L.; Mukherjee, S.; Wei, X.; Chou, G.; Wang, Z.T.; Mani, S. Protective effect of naringenin against experimental colitis via suppression of Toll-like receptor 4/NF-kappaB signalling. Br. J. Nutr. 2013, 110, 599-608.

37. Kim, D.S.; Han, J.H.; Kwon, H.J. NF-kappaB and c-Jun-dependent regulation of macrophage inflammatory protein-2 gene expression in response to lipopolysaccharide in RAW 264.7 cells. Mol. Immunol. 2003, 40, 633-643.

38. Islam, M.S.; Yoshida, H.; Matsuki, N.; Ono, K.; Nagasaka, R.; Ushio, H.; Guo, Y.; Hiramatsu, T.; Hosoya, T.; Murata, T.; et al. Antioxidant, free radical-scavenging, and NF-kappaB-inhibitory activities of phytosteryl ferulates: Structure-activity studies. J. Pharmacol. Sci. 2009, 111, 328-337.

39. Nagasaka, R.; Chotimarkorn, C.; Shafiqul, I.M.; Hori, M.; Ozaki, H.; Ushio, H. Anti-inflammatory effects of hydroxycinnamic acid derivatives. Biochem. Biophys. Res. Commun. 2007, 358, 615-619.

40. Murakami, A.; Nakamura, Y.; Koshimizu, K.; Takahashi, D.; Matsumoto, K.; Hagihara, K.; Taniguchi, H.; Nomura, E.; Hosoda, A.; Tsuno, T.; et al. FA15, a hydrophobic derivative of ferulic acid, suppresses inflammatory responses and skin tumor promotion: Comparison with ferulic acid. Cancer Lett. 2002, 180, 121-129.

41. Ronchetti, D.; Impagnatiello, F.; Guzzetta, M.; Gasparini, L.; Borgatti, M.; Gambari, R.; Ongini, E. Modulation of iNOS expression by a nitric oxide-releasing derivative of the natural antioxidant ferulic acid in activated RAW 264.7 macrophages. Eur. J. Pharmacol. 2006, 532, 162-169.

42. Hirata, A.; Murakami, Y.; Atsumi, T.; Shoji, M.; Ogiwara, T.; Shibuya, K.; Ito, S.; Yokoe, I.; Fugisawa, S. Ferulic acid dimer inhibits lipopolysaccharide-stimulated cyclooxygenase-2 expression in macrophages. In Vivo 2005, 19, 849-853.

43. Mendes Sdos, S.; Candi, A.; Vansteenbrugge, M.; Pignon, M.R.; Bult, H.; Boudjeltia, K.Z.; Munaut, C.; Raes, M. Microarray analyses of the effects of NF-kappaB or PI3K pathway inhibitors on the LPS-induced gene expression profile in RAW264.7 cells: Synergistic effects of rapamycin on LPS-induced MMP9-overexpression. Cell Signal. 2009, 21, 1109-1122.

Sample Availability: Samples of the aqueous extract of tomato and feluric acid are available from the authors.

(C) 2015 by the authors; licensee MDPI, Basel, Switzerland. This article is an open access article distributed under the terms and conditions of the Creative Commons Attribution license (http://creativecommons.org/licenses/by/4.0/). 